\title{
Antenatal Diagnosis of Achondrogenesis Type II
}

\author{
Kodandapani S, ${ }^{1}$ Ramkumar $\mathrm{V}^{1}$ \\ 'Department of Obstetrics and Gynaecology, Kasturba Medical College, Manipal, India
}

\section{ABSTRACT}

Achondrogenesis is a lethal congenital chondrodystrophy characterized by extreme micromelia, small thorax and polyhydramnios. We describe a case of achondrogenesis type II (Langer-Saldino achondrogenesis). Prenatal ultrasonography at 22-weeks gestation revealed a fetus with large head, short neck and chest, prominent abdomen and short limbs. Pregnancy was terminated. Radiologic examination of neonate revealed features of achondrogenesis type II. Routine ultrasound screening made early detection and timely management possible.

Key Words: achondrogenesis, antenatal, chondrodystroph, congenital

\section{INTRODUCTION}

Skeletal dysplasia is one of the bone abnormalities which can be detected by prenatal ultrasound with good accuracy. Few types of skeletal dysplasia are lethal, hence if diagnosed in time, can be offered termination. Amongst the lethal skeletal dysplasias, Achondrogenesis is one of the lethal skeletal dysplasias. Hence while performing ultrasound; sonologists should be vigilant about length of long bones, thorax and liquor. Also interesting fact is that whenever polyhydramnios is noted in second trimester, lethal skeletal dysplasia should be thought of. We present a case of achondrogenesis which taught us valuable points while performing ultrasound.

\section{CASE REPORT}

A 26 year female with gravid third presented at 22 weeks gestation. She had a healthy 8 -year old boy and the second pregnancy was terminated presumably at 7 months amenorrhea due to limb anomalies.

Anomaly scan showed large head with biparietal diameter corresponding to 24 weeks gestation with no obvious intracranial pathology (Figure 1). It had small chest with thoracic circumference of $130 \mathrm{~mm}(<2 \mathrm{SD})$, very short femur of $10.3 \mathrm{~mm}$ corresponding to 13 weeks gestation and other long bones also appeared short. Polyhydramnios was present and nuchal thickness was $12 \mathrm{~mm}$. There were no hand and facial abnormalities.

A presumptive diagnosis of lethal skeletal dysplasia was made because of severe micromelia, small thorax and polyhydramnios. Patient opted for termination of pregnancy. Labor was induced with misoprostol and stillborn male fetus weighing $1 \mathrm{Kg}$ was delivered vaginally. Gross features were large head, subcutaneous edema, severe micromelia, small thorax and normal hands, feet and facial features (Figure 2).

The radiographic features were hypomineralization, flattening of spine and ribs, severe micromelia, with widened metaphyseal ends (Figure 3). Pelvis was characterized by absence of ossification of pubis and hypoplastic iliac wings. Calvarial ossification was normal. There were no bone deformities or fractures.

\section{DISCUSSION}

More than 210 skeletal dysplasias are listed. The four most common skeletal dysplasias are thanatophoric

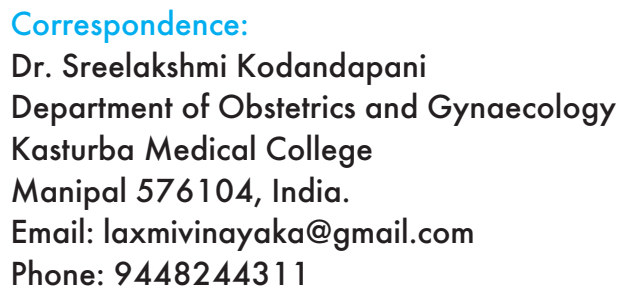


dysplasia, achondroplasia, osteogenesis imperfecta and achondrogenesis. Thanatophoric dysplasia and achondrogenesis account for $62 \%$ of all skeletal dysplasias. The prevalence of lethal skeletal dysplasia is 0.9 per 10000 births. Achondrogenesis occurs in approximately 6.4 per 100000 births and leads to death either in utero or neonatal period. ${ }^{1}$

Achondrogenesis is a lethal chondrodystrophy characterized by extreme micromelia, short trunk and large head. Although four types are described types III and IV have overlapping features with II. There are significant difference between type I and II (Table 1).

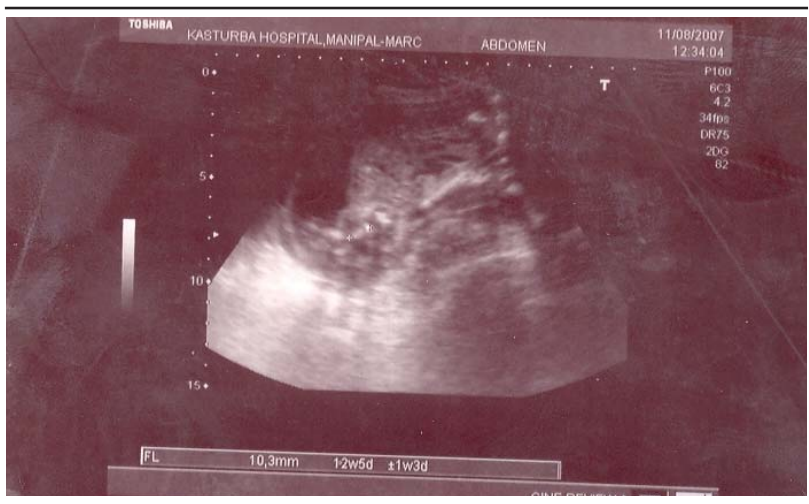

Figure 1. Ultrasound showing severe micromelia with femur length corresponding to 13 -weeks at 22-weeks gestation

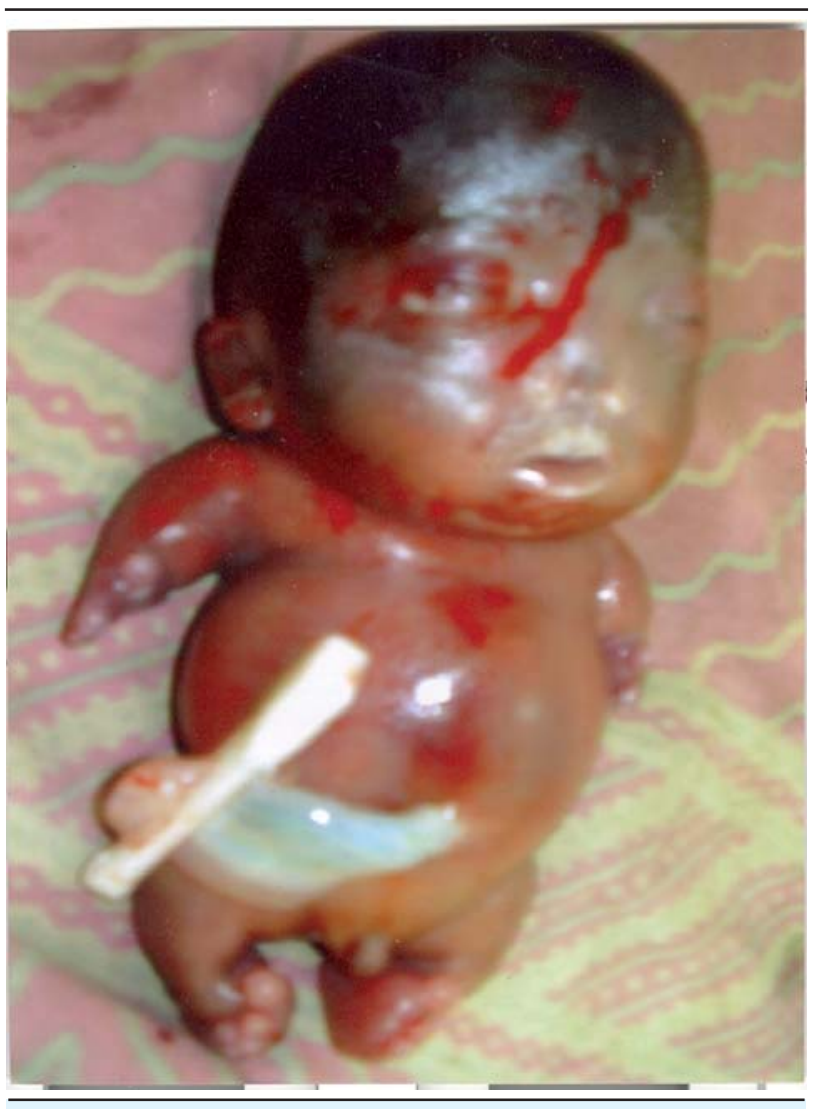

Figure 2. Postnatal photograph of fetus

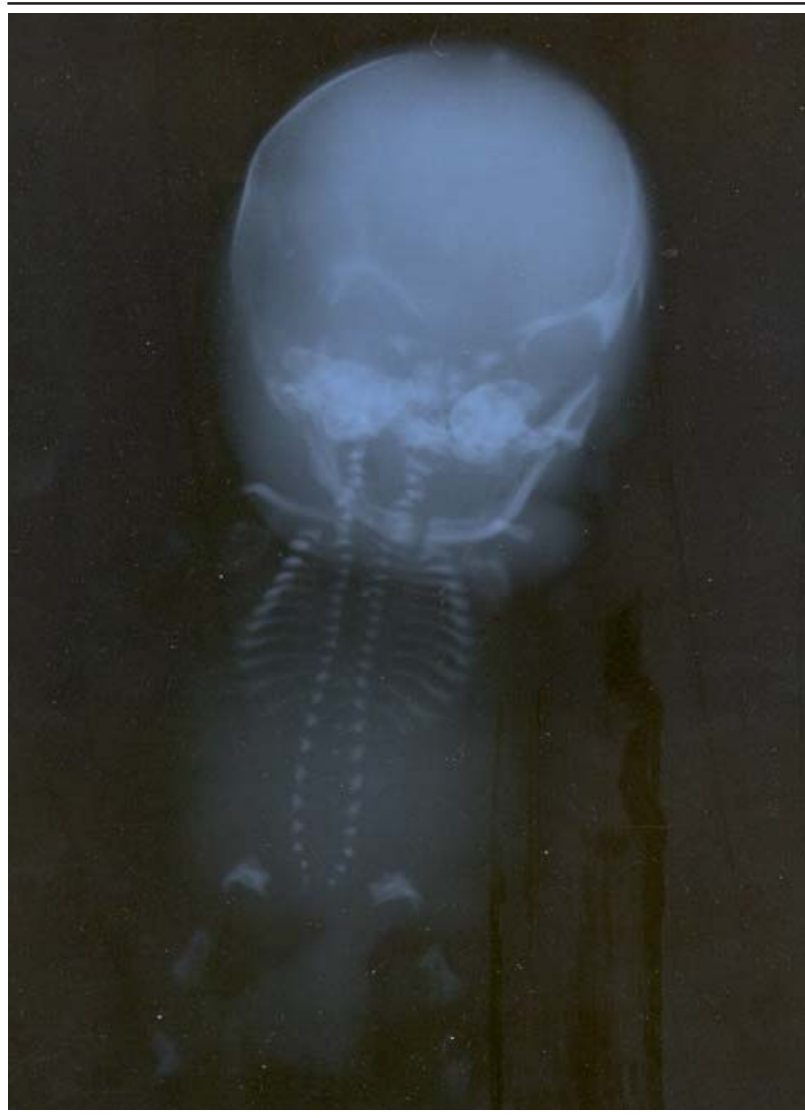

Figure 3. Postnatal radiograph showing hypomineralization of skeleton, very short long bones and widened metaphyseal ends

Achondrogenesis type I is a severe chondrodystrophy characterized radiographically by poor ossification of the spine and pelvic bones, which results in stillbirth or early death. It is further classified into type IA and type IB. Type II achondrogenesis presents with the same findings, but the mineralization deficit is less severe, long bones are less short and do not involve the axial skeleton. $^{3-5}$

Severe micromelia, small thorax and polyhydramnios provided the initial clues to the diagnosis of lethal skeletal dysplasia in our case. The key findings pointing to the diagnosis of achondrogenesis type II were extreme micromelia, lack of vertebral and sacral ossification, normal appearance of calvarium and absence of bone deformity or fracture. Polyhydramnios was due to esophageal compression, and hydropic appearance of the fetus resulted from redundancy of soft tissue mass over a limited skeletal frame.

Although type I achondrogenesis is autosomal recessive in inheritance, type II is either autosomal dominant or sporadic. In our case, since the previous pregnancy resulted in a fetus with probable skeletal dysplasia, this may imply autosomal dominant type of inheritance. No other family members were affected. 
Kodandapani et al. Antenatal Diagnosis of Achondrogenesis Type II

Table 1. Achondrogenesis: type I and II

\begin{tabular}{ll}
\hline Type I Parenti- Fraccaro & Type II Langer- Saldino \\
\hline Extreme micromelia & Prominent forehead \\
$\begin{array}{l}\text { Very short and thin ribs } \\
\text { Multiple rib fractures }\end{array}$ & Absence of rib fractures \\
$\begin{array}{l}\text { Poor ossification of skull, spine, ischium, pubis and iliac } \\
\text { bones }\end{array}$ & Normal calvarial ossification \\
\hline
\end{tabular}

Osteogenesis imperfecta and hypophosphatasia also present with demineralization but limb shortening is usually not severe. Since achondrogenesis is lethal, termination of pregnancy can be offered. Standard prenatal care is not altered when continuation of pregnancy is opted.
Achondrogenesis is a lethal skeletal dysplasia characterized by severe micromelia, small thorax and polyhydramnios. We describe a case detected by antenatal ultrasound at 22-weeks of gestation.

\section{REFERENCES}

1. Nyberg DA, Mc Gahan JP, Pretorius DH, Pilu G. Diagnostic Imaging of Fetal Anomalies. Baltimore: Williams \& Wilkins;2003. p. 661.

2. Thomas D, Lejeune R, Mortier G, Duprez L, Puttemans T, Lamy C. Achondrogenesis, type II [Online]. 2003 Jan 1415 [cited 2009 Apr 10]; Available from: URL:http://www. thefetus.net/page.php?id=1085

3. Lee HS, Doh JW, Kim CJ, Chi JG. Achondrogenesis type II (Langer-Saldino achondrogenesis): a case report. J Korean Med Sci. 2000 Oct 15;(5):604-8.
4. Geneva Foundation for Medical Education and Research. chondrogenesis, type II [Online]. [cited 2009 Apr 10]; Available from: URL:http://www.gfmer.ch/genetic diseases_v2/gendis_detail_list.php?cat3=858

5. Wikipedia. Achondrogenesis type 2 [Online]. [cited 2009 Apr 10]; Available from: URL:http://en.wikipedia.org/wiki/ Achondrogenesis_type_2 